\title{
BMJ
}

\section{Provision of acute stroke care and associated factors in a multiethnic population: prospective study with the South London Stroke Register}

\author{
Juliet Addo, clinical research associate, ${ }^{1,3}$ Ajay Bhalla, consultant stroke physician, ${ }^{2}$ Siobhan Crichton, research \\ assistant, ${ }^{1}$ Anthony G Rudd, consultant stroke physician, ${ }^{1,2}$ Christopher McKevitt, reader in social science and \\ health, ${ }^{1}$ Charles D A Wolfe, professor of public health medicine ${ }^{1,3}$
}

\section{'King's College London, Division of Health and Social Care Research, London SE1 3QD, UK \\ ${ }^{2}$ Department of Health and Ageing, Guy's and St Thomas' NHS Foundation Trust, St Thomas' Hospital, London, UK \\ ${ }^{3}$ National Institute for Health Research Comprehensive Biomedical Research Centre, Guy's and St Thomas' NHS Foundation Trust, London, UK Correspondence to: J Addo Juliet.addo@kcl.ac.uk}

Cite this as: $B M J$ 2011;342:d744 doi:10.1136/bmi.d744

\section{ABSTRACT}

Objectives To investigate time trends in receipt of effective acute stroke care and to determine the factors associated with provision of care.

Design Population based stroke register.

Setting South London.

Participants 3800 patients with first ever ischaemic stroke or primary intracerebral haemorrhage registered between January 1995 and December 2009.

Main outcome measures Acute care interventions, admission to hospital, care on a stroke unit, acute drugs, and inequalities in access to care.

Results Between 2007 and 2009, 5\% (33/620) of patients were still not admitted to a hospital after an acute stroke, particularly those with milder strokes, and $21 \%(124 / 584)$ of patients admitted to hospital were not admitted to a stroke unit. Rates of admission to stroke units and brain imaging, between 1995 and 2009, and for thrombolysis, between 2005 and 2009, increased significantly $(P<0.001)$. Black patients compared with white patients had a significantly increased odds of admission to a stroke unit (odds ratio 1.76, 95\% confidence interval 1.35 to 2.29 , P<0.001) and of receipt of occupational therapy or physiotherapy $(1.90,1.21$ to 2.97, $\mathrm{P}=0.01$ ), independent of age or stroke severity. Patients with motor or swallowing deficits were also more likely to be admitted to a stroke unit $(1.52,1.12$ to 2.06 , $\mathrm{P}=0.001$ and $1.32,1.02$ to $1.72, \mathrm{P}<0.001$, respectively). Length of stay in hospital decreased significantly between 1995 and 2009 ( $P<0.001)$. The odds of brain imaging were lowest in patients aged 75 or more years $(P=0.004)$ and those of lower socioeconomic status ( $P<0.001)$. The likelihood of those with a functional deficit receiving rehabilitation increased significantly over time ( $\mathrm{P}<0.001)$. Patients aged 75 or more were more likely to receive occupational therapy or physiotherapy $(\mathrm{P}=0.002)$.

Conclusion Although the receipt of effective acute stroke care improved between 1995 and 2009, inequalities in its provision were significant, and implementation of evidence based care was not optimal.

\section{INTRODUCTION}

Care of people with stroke provided by multidisciplinary teams in a stroke unit results in better outcomes. ${ }^{1}$ Observational studies and trials of acute stroke care of patients from Europe, Australia, and Argentina have reported considerable variation in the processes of stroke care and associated outcomes..$^{2-5}$ Differences in hyperacute stroke management are possible reasons for the poorer reported outcomes in the United Kingdom. ${ }^{67}$ Previous research on patients admitted to hospitals in south London between 1995 and 2000 identified sociodemographic inequalities in rates of admission to both hospital and stroke units and in receipt of brain imaging. ${ }^{8}$ Patients who have a stroke during hospital stay in south London have been reported to have poorer access to brain imaging and care in a stroke unit than patients admitted after the stroke. $^{9}$

International, national, and regional guidelines make recommendations for care across the whole stroke pathway but with an emphasis on acute stroke care. ${ }^{10-14}$ Policy documents, including the National Service Framework for Older People (2001), the National Audit Office Report (2005 and 2010), and the National Stroke Strategy (2007) have aimed at improving services for people who have had a stroke in England. ${ }^{15-17}$ National audit analyses provide some evidence that the quality of stroke care in the United Kingdom is improving, but these studies only provide a snapshot of care for about 60 patients in each centre, without detailed clinical characteristics, and are only carried out every two or three years. ${ }^{18}$ We investigated the time trends in receipt of effective acute care interventions after a stroke in a multiethnic population in south London and determined the factors associated with their uptake.

\section{METHODS}

Identification of cases

Data for this analysis were derived from the South London Stroke Register, an ongoing population based register that has prospectively recorded first ever strokes 
in patients of all age groups living within a geographically defined area of south London since 1995. In this analysis we used data collected between 1995 and 2009, divided into five year groups (1995-7, 19982000, 2001-3, 2004-6, and 2007-9). At the 2001 census, the population of the area covered by the register was 271 817: $63 \%$ of the population were white, $9 \%$ black Caribbean, 15\% black African, and 13\% from other ethnic groups. The detailed methods of notification of patients and data collection have been described previously. ${ }^{1920}$ Briefly, patients were identified using multiple sources of notification by specially trained study nurses and fieldworkers. All data were collected prospectively. Patients or their relatives gave written informed consent to participate in the study. Hospital surveillance of admissions for stroke included two teaching hospitals within and two teaching hospitals outside the study area, and one general district hospital outside the study area. Community surveillance for stroke included patients under the care of all general practitioners within and on the borders of the study area. Notification sources included accident and emergency records, hospital wards, requests for brain imaging, death certificates, coroner's records, hospital medical staff, community therapists, bereavement officers, and hospital based stroke registries. Capturerecapture models estimated completeness of case ascertainment in this population to be around $80 \%{ }^{21}$ The diagnosis of stroke, using the World Health Organization clinical definition, was verified by a study clinician, and patients were examined within 48 hours of being notified to the South London Stroke Register where possible. We checked collected data with the patients' general practitioner and medical records. Patients with a subarachnoid haemorrhage were excluded because they have differing needs for acute care and are typically managed in neurosurgical wards following different protocols.

\section{Sociodemography and case mix}

Data on sociodemographic characteristics collected at initial assessment were age; sex; self definition of ethnic origin (1991 census question) stratified into white, black (black Caribbean, black African, and black other), and other ethnic group; socioeconomic status (registrar general's occupational codes), grouped into manual, non-manual, and economically inactive (student, unemployed, and unable to work because of disability or being a carer), and living circumstances before stroke (alone in private accommodation, with others in private accommodation, nursing or hospital care). We obtained the clinical details at the time of maximal impairment. These included information on motor deficit, swallowing (using the $3 \mathrm{oz}(85 \mathrm{~mL})$ water swallow test), speech, visual impairments, and urinary incontinence. The level of consciousness was assessed using the Glasgow coma scale dichotomised into scores of less than 13 (impaired consciousness) and 13 or more. ${ }^{22}$ Classification of stroke subtype (ischaemic stroke or primary intracerebral haemorrhage) was based on results from at least one of computed tomography or magnetic resonance imaging. Where there was no known pathological classification of stroke subtype, we classed cases as undefined.

\section{Processes of acute stroke care}

We examined a range of indicators of the processes of care after an acute stroke suggested to be useful proxy measures for the overall quality of stroke care. ${ }^{12}$ These were admission to hospital, admission to a stroke unit, more than $50 \%$ of hospital admission spent in a stroke unit, brain imaging, and the swallow test. We examined the indicators for provision of rehabilitation therapy (physiotherapy assessment within 72 hours, occupational therapy within seven days, and speech and language therapy) within seven days for those with recorded deficits for 2005-9, when data were collected for the register on these processes. The use of physiotherapy and occupational therapy was considered appropriate for patients with any paralysis, visual field defects, and sensory impairments in the acute phase. Speech and language therapy was considered appropriate in patients with dysphasia, dysarthria, and dysphagia or a failed swallow test result. Other interventions for which data were collected only between 2005 and 2009 included thrombolysis within three hours of symptom onset if ischaemic stroke; receipt of aspirin at anytime within the first week of stroke or within 48 hours if ischaemic stroke; enteral feeding (nasogastric or percutaneous endoscopic gastrostomy), after a failed swallow test result; and provision of intravenous fluids.

\section{Statistical analysis}

We used one way analysis of variance to investigate the univariate association between the time intervals and continuous variables and the $\chi^{2}$ test for categorical variables. The $\chi^{2}$ test for trend was used to examine trends over time in rates of admission to hospital, investigations carried out, and rehabilitation services received. We used multivariable logistic regression models to examine the impact of sociodemographic variables (age, sex, socioeconomic status, and ethnicity) and case mix (Glasgow coma scale score, urinary incontinence, motor and swallowing deficit, and stroke subtype) on the processes of care and to examine time trends in the process of care measures. We present the odds ratios and $95 \%$ confidence intervals estimated by these models. The sample was confined to complete cases for the multivariable analysis with no missing values in the associated factors considered. Information missing on sociodemographics, clinical characteristics, and processes of care ranged from $0.3 \%$ for sex to $10.8 \%$ for the swallow test and $11.6 \%$ for speech deficits. Data on aspirin given within 48 hours was collected only from July 2005, resulting in a significant amount of missing data for that year. We carried out a sensitivity analysis to examine the effect of restricting analyses of acute care processes to only those who survived more than 24 hours. Stata version 11.0MP was used for the statistical analyses. 
RESULTS

Of 3800 patients with first ever stroke between 1995 and $2009,3330(87.6 \%)$ were treated in hospital after the stroke and 388 of these $(11.7 \%)$ experienced stroke while in hospital. The mean age at onset was 71.1 (SD 14.1) years. Table 1 lists the sociodemographic factors, severity of stroke, and stroke subtype of the patients.

Trends in acute care interventions

Table 2 reports the specific interventions in each year group and the trends over the 15 year study period.
The proportion of patients admitted to hospital for an acute stroke increased significantly over the study period: $54 \%$ were admitted to a stroke unit and this significantly increased from $18.9 \%(141 / 736)$ in 1995-7 to $78.4 \%(460 / 584)$ in 2007-9. Similarly, the proportion of patients spending more than $50 \%$ of their hospital stay on a stroke unit increased significantly, from $10.4 \%(76 / 733)$ in $1995-7$ to $72.0 \%(462 / 642)$ in 2007-9. Length of stay decreased significantly over the study period, from a median 21 (interquartile range 8-52) days in 1995-7 to 13 (5-36.5) days in

Table 1| Sociodemographic characteristics and neurological deficits of patients with stroke over study period, 1995-2009. Values are numbers (percentages) unless stated otherwise

\begin{tabular}{|c|c|c|c|c|c|c|}
\hline \multirow[b]{2}{*}{ Characteristics } & \multicolumn{5}{|c|}{ Study period } & \multirow[b]{2}{*}{$P$ value } \\
\hline & $\begin{array}{c}1995-7 \\
(n=907)\end{array}$ & $\begin{array}{c}1998-2000 \\
(n=810)\end{array}$ & $\begin{array}{c}2001-3 \\
(n=757)\end{array}$ & $\begin{array}{l}2004-6 \\
(n=706)\end{array}$ & $\begin{array}{l}2007-9 \\
(n=620)\end{array}$ & \\
\hline Mean (SD) age (years) & $72.7(13.0)$ & 71.5 (13.5) & $71.0(14.2)$ & $70.0(14.6)$ & $69.8(15.6)$ & 0.002 \\
\hline Men & $448(49.4)$ & $405(50.0)$ & $376(49.7)$ & $390(55.2)$ & $302(49.4)$ & 0.12 \\
\hline \multicolumn{7}{|l|}{ Ethnic group: } \\
\hline White & $731(80.6)$ & $597(73.7)$ & $532(70.3)$ & $473(67.0)$ & $421(67.9)$ & \multirow{4}{*}{$<0.001$} \\
\hline Black & $134(14.8)$ & $150(18.5)$ & $149(19.7)$ & $159(22.5)$ & $149(24.0)$ & \\
\hline Other & $39(4.3)$ & $44(5.4)$ & $39(5.2)$ & $53(7.5)$ & $36(5.8)$ & \\
\hline Unknown & $3(0.3)$ & $19(2.4)$ & 37 (4.9) & $21(3.0)$ & $14(2.3)$ & \\
\hline \multicolumn{7}{|l|}{ Socioeconomic status: } \\
\hline Non-manual & $207(22.8)$ & $206(25.4)$ & $204(27.0)$ & $186(26.4)$ & $160(25.8)$ & \multirow{4}{*}{$<0.001$} \\
\hline Manual & $555(61.2)$ & $422(52.1)$ & $444(58.7)$ & $377(53.4)$ & $294(47.4)$ & \\
\hline Economically inactive & $118(13.0)$ & $128(15.8)$ & $72(9.5)$ & $109(15.4)$ & $122(19.7)$ & \\
\hline Unknown & $27(3.0)$ & $54(6.7)$ & 37 (4.9) & $34(4.8)$ & $44(7.1)$ & \\
\hline \multicolumn{7}{|l|}{ Living conditions before stroke: } \\
\hline Alone in private accommodation & $328(36.2)$ & $147(18.2)$ & $257(34.0)$ & $258(36.5)$ & $189(30.5)$ & \multirow{4}{*}{$<0.001$} \\
\hline With others in private accommodation & $456(50.3)$ & $162(20.0)$ & $404(53.4)$ & $380(53.8)$ & $355(57.3)$ & \\
\hline Nursing home or other & $87(9.6)$ & $43(5.3)$ & $65(8.6)$ & $54(7.7)$ & $73(11.8)$ & \\
\hline Unknown & $36(4.0)$ & $458(56.5)$ & $31(4.1)$ & $14(2.0)$ & $3(0.5)$ & \\
\hline \multicolumn{7}{|l|}{ Stroke subtype: } \\
\hline Infarction & $680(75.0)$ & $621(76.7)$ & $606(80.1)$ & $589(83.4)$ & $536(86.5)$ & \multirow{4}{*}{$<0.001$} \\
\hline Primary intracerebral haemorrhage & $118(13.0)$ & $136(16.8)$ & $108(14.3)$ & $102(14.5)$ & $40(6.5)$ & \\
\hline Unclassified & $107(11.8)$ & $41(5.1)$ & $30(4.0)$ & $7(1.0)$ & 0 & \\
\hline Unknown & $2(0.2)$ & $12(1.5)$ & $13(1.7)$ & $8(1.1)$ & $44(7.1)$ & \\
\hline \multicolumn{7}{|l|}{ Glasgow coma scale score: } \\
\hline «13 (impaired consciousness) & $258(28.5)$ & $189(23.3)$ & $205(27.1)$ & $178(25.2)$ & $171(27.6)$ & \multirow{3}{*}{0.10} \\
\hline$\geq 13$ & $627(69.1)$ & $591(73.0)$ & $496(65.5)$ & 507 (71.8) & $425(68.6)$ & \\
\hline Unknown & $22(2.4)$ & $30(3.7)$ & $56(7.4)$ & $21(3.0)$ & $24(3.9)$ & \\
\hline \multicolumn{7}{|l|}{ Incontinence: } \\
\hline Yes & $438(48.3)$ & $316(39.0)$ & $312(41.2)$ & $298(42.2)$ & $250(40.5)$ & \multirow{3}{*}{$<0.001$} \\
\hline No & $425(46.9)$ & $413(51.0)$ & $358(47.3)$ & $391(55.4)$ & $358(57.9)$ & \\
\hline Unknown & $44(4.9)$ & $81(10.0)$ & $87(11.5)$ & $17(2.4)$ & $10(1.6)$ & \\
\hline \multicolumn{7}{|l|}{ Speech deficit: } \\
\hline Yes & $555(61.2)$ & 399 (49.3) & 491 (64.9) & $512(72.5)$ & $462(74.5)$ & \multirow{3}{*}{0.002} \\
\hline None & $233(25.7)$ & 109 (13.5) & $215(28.4)$ & $191(27.1)$ & $148(23.9)$ & \\
\hline Unknown & 119 (13.1) & $302(37.3)$ & $51(6.7)$ & $3(0.4)$ & $10(1.6)$ & \\
\hline \multicolumn{7}{|l|}{ Swallow impairment: } \\
\hline Yes & $416(45.9)$ & $289(35.7)$ & $277(36.6)$ & $235(33.3)$ & $178(28.7)$ & \multirow{3}{*}{$<0.001$} \\
\hline None & $439(48.4)$ & $442(54.6)$ & $383(50.6)$ & $386(54.7)$ & $345(55.7)$ & \\
\hline Unknown & $52(5.7)$ & $79(9.8)$ & $97(12.8)$ & $85(12.0)$ & $97(15.7)$ & \\
\hline \multicolumn{7}{|l|}{ Motor deficit: } \\
\hline Present & 787 (86.8) & $641(79.1)$ & 609 (80.5) & 587 (83.1) & $511(82.4)$ & \multirow{3}{*}{$<0.001$} \\
\hline None & $94(10.4)$ & $113(14.0)$ & 101 (13.3) & $110(15.6)$ & $100(16.1)$ & \\
\hline Unknown & $26(2.9)$ & $56(6.9)$ & $47(6.2)$ & $9(1.3)$ & $9(1.5)$ & \\
\hline
\end{tabular}


Table 2 | Interventions in acute stroke phase over study period. Values are numbers of participants with process/total number of participants with data on process measure (\%) unless stated otherwise

\begin{tabular}{|c|c|c|c|c|c|c|}
\hline \multirow[b]{2}{*}{ Process measure } & \multicolumn{5}{|c|}{ Study period } & \multirow[b]{2}{*}{ Pfortrend } \\
\hline & $\begin{array}{l}1995-7 \\
(n=907)\end{array}$ & $\begin{array}{l}1998-2000 \\
(n=810)\end{array}$ & $\begin{array}{l}2001-3 \\
(n=757)\end{array}$ & $\begin{array}{l}2004-6 \\
(n=706)\end{array}$ & $\begin{array}{l}2007-9 \\
(n=620)\end{array}$ & \\
\hline Hospital admission & $745 / 907$ (82.1) & $693 / 810(85.6)$ & $647 / 757(85.5)$ & $658 / 706(93.2)$ & $587 / 620(94.7)$ & $<0.001$ \\
\hline Stroke unit admission* & $141 / 736(18.9)$ & $245 / 678(35.4)$ & $424 / 640(65.5)$ & $503 / 644(76.4)$ & $460 / 584(78.4)$ & $<0.001$ \\
\hline$>50 \%$ of stay on stroke unit* & $76 / 733(10.4)$ & $60 / 659(9.1)$ & $306 / 622(49.2)$ & $462 / 642(72.0)$ & $413 / 574(72.0)$ & $<0.001$ \\
\hline $\begin{array}{l}\text { Median (interquartile range) } \\
\text { length of stay (days) }\end{array}$ & $21(8-52)$ & $21(8-54)$ & $16(6-51)$ & $14(4-37)$ & $13(5-36.5)$ & $<0.001$ \\
\hline Brain imaging & $759 / 891(85.2)$ & $726 / 790(91.9)$ & $678 / 739(91.8)$ & $674 / 685((98.4)$ & $554 / 556(99.6)$ & $<0.001$ \\
\hline Swallow test* & $710 / 739(96.1)$ & $632 / 682(92.7)$ & $584 / 644(90.7)$ & $594 / 657(90.4)$ & $516 / 587(87.9)$ & $<0.001$ \\
\hline
\end{tabular}

*Analysis limited to patients admitted to hospital.

2007-9. Most of the patients $(92.6 \%$, 3391/3661) had brain imaging and this increased significantly over time: from $85.2 \%(759 / 891)$ in $1995-7$ to $99.6 \%$ (554/556) in 2007-9. The proportion of patients who were assessed for swallowing decreased significantly between 1995 and 2009, from 96.1\% (710/739) in $1995-7$ to $87.9 \%(516 / 587)$ in $2007-9$.

Table 3 reports on those patients who were eligible for interventions and those who actually received these between 2005 and 2009. The proportion of patients with ischaemic stroke who received thrombolysis increased significantly, from $2.8 \%(6 / 217)$ in 2005 to $20.1 \%(32 / 159)$ in 2008 and $15.7 \%(27 / 172)$ in 2009. A non-significant increase was observed in the proportion of patients with ischaemic stroke prescribed aspirin at any time within the acute (first seven days) phase $(84.7 \%(133 / 157)$ in 2005 and $89.8 \%(149 / 166)$ in $2009, \mathrm{P}=0.10)$ or within 48 hours after an acute stroke $(74.2 \%(109 / 147)$ in 2005 and $78.4 \%(80 / 102)$ in $2009, \mathrm{P}=0.36)$. The proportion of patients fed by the enteral route after a failed swallow test result also increased significantly, from $40.6 \%(28 / 69)$ in 2005 to $66.0 \%(33 / 50)$ in $2009(\mathrm{P}=0.03)$. The proportion of patients with speech or swallowing difficulties receiving speech and language therapy increased non-significantly from $59.6 \%(96 / 161)$ in 2005 to $66.3 \%(67 / 101)$ in $2009(\mathrm{P}=0.53)$.

Factors associated with acute care interventions

Table 4 shows the associations between sociodemographic characteristics, case mix, and acute care interventions. Haemorrhagic stroke, reduced scores on the Glasgow coma scale, swallowing deficits, and incontinence were significantly (all $\mathrm{P}<0.001$ ) associated with hospital admission. Patients of black ethnicity had significantly increased odds of admission to a stroke unit compared with those of white ethnicity $(\mathrm{P}<0.001)$ even after adjusting for age and stroke severity. The association remained significant after excluding those who died within the first 24 hours. Patients with a higher level of consciousness (Glasgow coma scale score $\geq 13$ ) were more likely to be admitted to a stroke unit. This association, however, ceased to be significant after excluding those who died within the first day of admission $(\mathrm{P}=0.17)$. Patients who had motor deficits or swallowing deficits were also more likely to be admitted to a stroke unit $(\mathrm{P} \leq 0.001)$. Older patients $(\mathrm{P}=0.005)$ and those of lower socioeconomic status $(\mathrm{P}<0.001)$ were less likely to have brain imaging done, whereas those with haemorrhagic stroke had an increased odds of undergoing brain imaging $(\mathrm{P}=0.02)$. The observed association between increasing age and odds of brain imaging was non-significant after excluding those who died within the first day of stroke $(\mathrm{P}=0.07)$. The odds of receiving these interventions increased significantly over the study period $(\mathrm{P}<0.001)$.

Table 5 shows the associations between sociodemographic characteristics, case mix, and the provision of rehabilitation therapies. The analysis was limited to patients who were admitted to hospital. Patients who were older $(\mathrm{P}=0.002)$, were of black ethnicity $(\mathrm{P}=0.01)$, had higher levels of consciousness (Glasgow coma scale score $\geq 13)$, were incontinent $(\mathrm{P}=0.04)$, and had swallowing deficits $(\mathrm{P}=0.03)$ were significantly more likely to receive physiotherapy or occupational therapy. Patients with ischaemic stroke $(\mathrm{P}<0.001)$, increased level of consciousness $(\mathrm{P}=0.004)$, incontinence $(\mathrm{P}<0.001)$, and swallowing deficits $(\mathrm{P}<0.001)$ were significantly more likely to receive speech and language therapy. The trend between year of stroke and receipt of rehabilitation therapy or speech and language therapy was significant $(\mathrm{P}<0.001)$.

\section{DISCUSSION}

The introduction of evidence based guidelines has been reported to be associated with significant improvements in the process of care in certain settings, particularly when introduced in the context of rigorous evaluations, yet how this relates to stroke care is not documented in detail. ${ }^{23} \mathrm{We}$ found a considerable increase in the proportion of patients receiving effective interventions for acute stroke care in a multiethnic population and identified inequalities of access to interventions that improve outcomes. Patients with more severe strokes were more likely to be admitted to hospital, and those of black ethnicity as well as those with motor and swallowing deficits were more likely to be admitted to stroke units. The trend towards increased provision of evidence based care after an acute stroke in this population possibly reflects the adoption of national guidelines driven by targets set by the National Service Framework for Older People, and 
Table 3|Proportion of patients eligible for and receiving intervention for acute stroke, 2005-9. Values are number receiving intervention/number eligible for intervention (\%) unless stated otherwise

\begin{tabular}{|c|c|c|c|c|c|c|}
\hline \multirow[b]{2}{*}{ Variables } & \multicolumn{5}{|c|}{ Study period } & \multirow[b]{2}{*}{$P$ for trend } \\
\hline & $2005(n=270)$ & $2006(n=229)$ & $2007(n=229)$ & $2008(n=200)$ & $2009(n=200)$ & \\
\hline No with ischaemic stroke & 221 & 180 & 195 & 162 & 179 & - \\
\hline Thrombolysis & $6 / 217$ (2.8) & $13 / 173(7.5)$ & 26/192 (13.5) & $32 / 159(20.1)$ & $27 / 172(15.7)$ & $<0.001$ \\
\hline Aspirin started at any time in acute phase* & $133 / 157(84.7)$ & $140 / 175(80.0)$ & $166 / 190(87.4)$ & $136 / 156(87.2)$ & $149 / 166(89.8)$ & 0.10 \\
\hline Aspirin started by 48 hours after stroke & $109 / 147(74.2)$ & $124 / 171(72.5)$ & $149 / 186(80.1)$ & $93 / 129(72.1)$ & $80 / 102(78.4)$ & 0.36 \\
\hline No with failed swallow screen $†$ & 70 & 75 & 69 & 52 & 55 & \multirow{2}{*}{0.03} \\
\hline Fed by enteral route $\neq$ & $28 / 69(40.6)$ & $40 / 74(54.1)$ & $39 / 68(57.4)$ & $24 / 51(47.1)$ & $33 / 50(66.0)$ & \\
\hline Intravenous fluids $†$ & $130 / 236(55.1)$ & $123 / 203(60.6)$ & $116 / 209(55.5)$ & $115 / 180(63.9)$ & $92 / 183(50.3)$ & 0.64 \\
\hline No requiring physiotherapy or occupational therapy & 213 & 181 & 196 & 157 & 158 & \multirow{2}{*}{0.61} \\
\hline Physiotherapy or occupational therapy received & $168 / 209(80.4)$ & $155 / 181(85.6)$ & $155 / 196(79.1)$ & $126 / 148(85.1)$ & $122 / 138(88.4)$ & \\
\hline No requiring speech and language therapy $\dagger$ & 166 & 168 & 167 & 139 & 128 & \multirow{2}{*}{0.53} \\
\hline Speech and language therapy received & $96 / 161(59.6)$ & $107 / 164(65.2)$ & $105 / 166(63.2)$ & $81 / 133(60.9)$ & $67 / 101(66.3)$ & \\
\hline
\end{tabular}

*Within first seven days of stroke.

tAnalysis limited to patients admitted to hospital.

‡Nasogastric or percutaneous endoscopic gastrostomy.

by evidence from audits showing a significant reduction in case fatality rates with care on a stroke unit. ${ }^{1724}$

\section{Comparison with other studies}

\section{Admission to hospital}

The pattern of increasing rates of admission to hospital and stroke units in these analyses is similar to reports from the National Sentinel Stroke Audits, monitoring the management of stroke in patients admitted to hospital in the United Kingdom. ${ }^{1825}$ Patients managed in hospitals that admit a large proportion of patients to stroke units are reported to have better processes of care and survival than those managed in hospitals with low stroke unit provisions. ${ }^{24}$ The introduction of thrombolysis as well as the expectations of patients may well have influenced practice over time. We found that even in recent years (2007-9), some patients $(5 \%)$ were still not admitted to a hospital after an acute stroke, particularly those with milder strokes, and $21 \%$ were not admitted to a stroke unit. It is difficult to judge whether these patients had appropriate assessment, diagnosis, and management in the home setting or on wards with no organised stroke care, but it is unlikely.

Hospital admission rates for acute stroke in population based studies in the United Kingdom have ranged from $56 \%$ to $91 \%{ }^{2627}$ These reported rates are similar to those in south London in the early 2000s. In the Auckland Regional Community Stroke Studies, the admission rates increased from $64.5 \%$ in $1981-2$ to $92.4 \%$ in 2002-3, similar to the findings in south London, indicating that this is a relevant population to undertake studies of trends in use of services and factors associated with access. ${ }^{28}$

Almost $12 \%$ of the patients in this study had their stroke during hospital admission. This is higher than that reported in other studies. ${ }^{2529-31}$ A large proportion of in-hospital strokes have been reported to occur in patients who had some form of invasive diagnostic, surgical, or other interventional procedure before the stroke event. ${ }^{29}$ A possible explanation for the high rates of strokes observed in patients admitted to hospital could be that invasive diagnostic or surgical procedures are undertaken more commonly in the hospitals in this study area, increasing the risk of in-hospital strokes. This significantly high proportion nevertheless emphasises the need for hospitals in the study area to have clearly outlined protocols for management of stroke in both patients from the community and those already admitted at the time of onset. ${ }^{9}$

\section{Stroke unit care and rehabilitation}

The overall rate for admission to a stroke unit of $54 \%$ is similar to reports from other countries. ${ }^{32}$ The rate of admission to stroke units of almost $80 \%$ in recent years in south London although not optimal was higher than that reported from some previous studies $^{33}$ but consistent with the rates of $83 \%$ in men and $80 \%$ in women reported in the Swedish National Quality Register for Stroke Care (Riks-Stroke). ${ }^{34}$

Admission to a stroke unit increased between 1995 and 2009 in this study, similar to the findings from the UK national audit, which shows admission to stroke units to have improved from $62 \%$ in 2006 to $74 \%$ in $2008 .^{25}$

Assessment of swallowing in this population decreased significantly, which is contrary to expectation based on the reports from the national audit. ${ }^{25}$ This finding is, however, likely to be an artefact of no recording in clinical notes.

The proportion of patients with speech and swallowing deficits receiving speech and language therapy increased only marginally between 2005 and 2009 . This is lower than expected and also lower than previously reported ${ }^{25}$ and may be related to the reduction in swallowing assessment or access to services for speech and language therapy.

\section{Acute drugs}

Despite the reported benefits of thrombolysis for patients with acute ischaemic stroke, variable rates of treatment have been reported in previous studies. ${ }^{3536}$ Almost all patients who received thrombolysis in this 


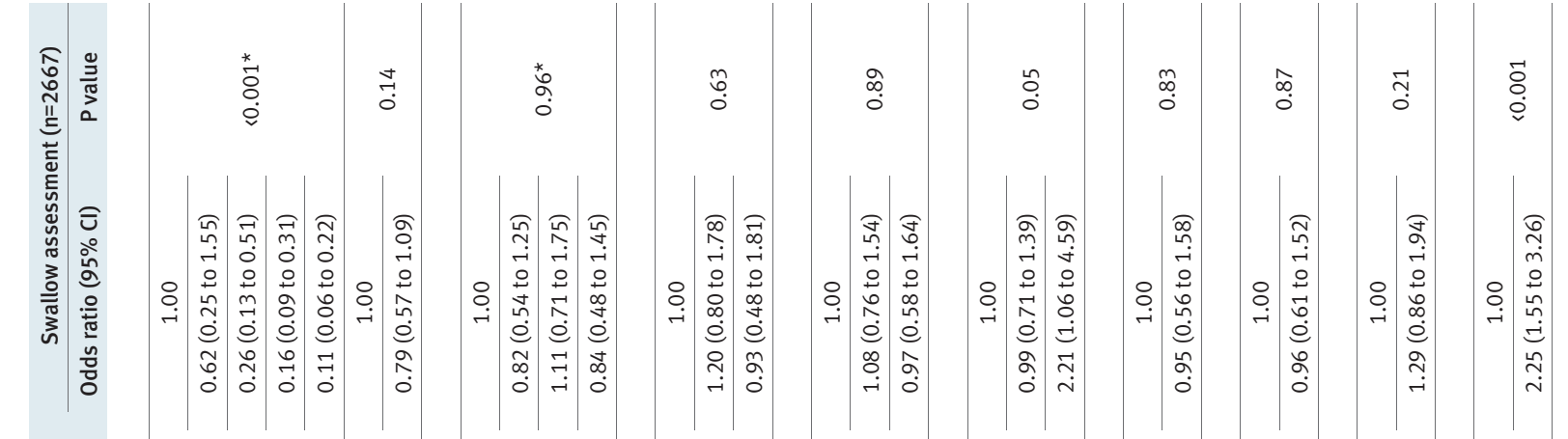

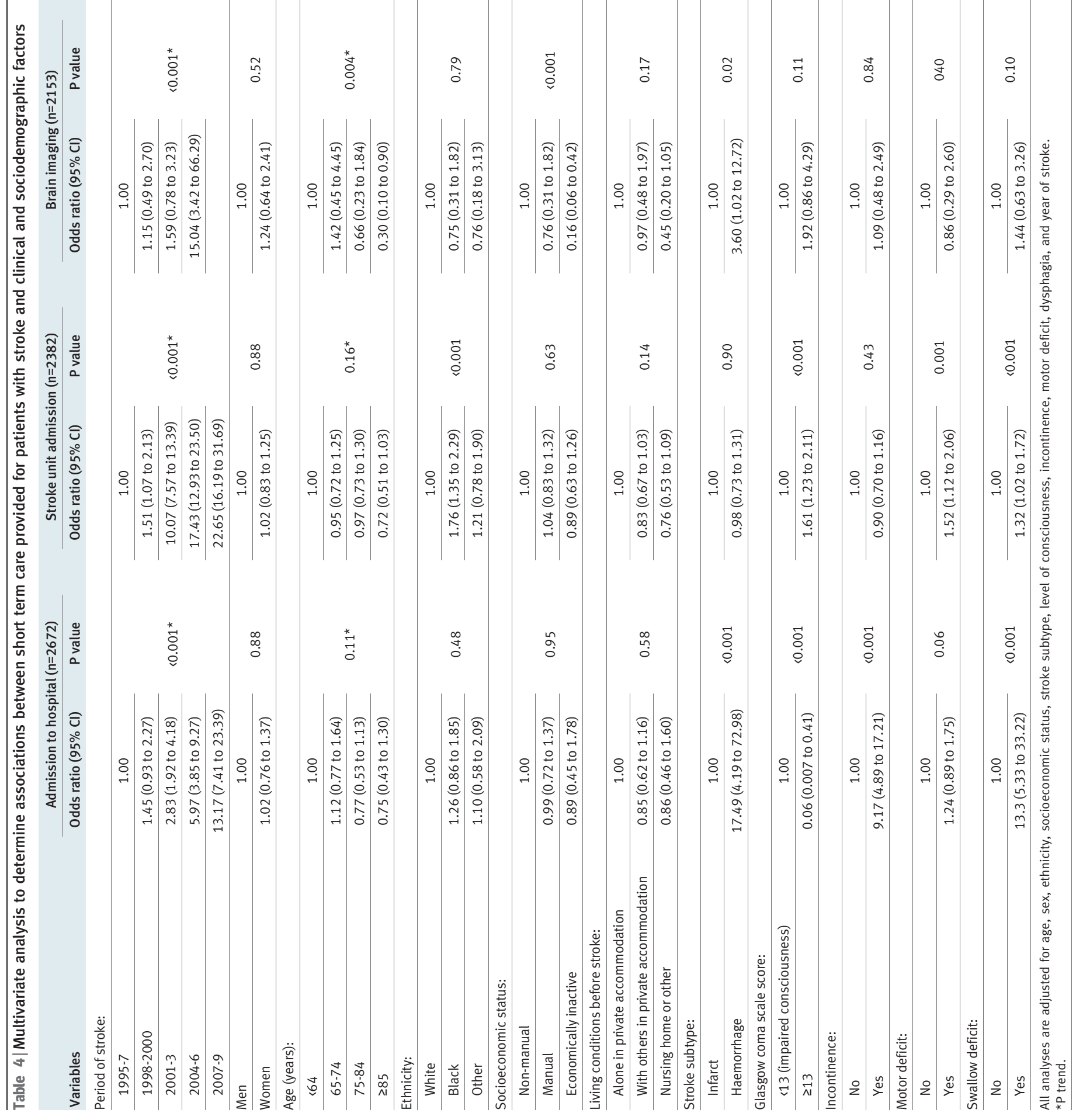


Table $5 \mid$ Multivariate analysis to determine associations between rehabilitation therapy and clinical and sociodemographic factors in patients with stroke

\begin{tabular}{|c|c|c|c|c|}
\hline \multirow[b]{2}{*}{ Variables } & \multicolumn{4}{|c|}{ Odds ratio $(95 \% \mathrm{Cl})$ for receipt of therapy } \\
\hline & $\begin{array}{l}\text { Physiotherapy or occupational } \\
\text { therapy }(n=1006)\end{array}$ & $P$ value & $\begin{array}{l}\text { Speech and language } \\
\text { therapy }(n=1000)\end{array}$ & $P$ value \\
\hline \multicolumn{5}{|l|}{ Year of stroke: } \\
\hline 2005 & 1.00 & \multirow{5}{*}{$<0.001^{\star}$} & 1.00 & \multirow{5}{*}{$<0.001^{\star}$} \\
\hline 2006 & 0.55 (0.03 to 9.81$)$ & & 1.57 (0.07 to 34.63) & \\
\hline 2007 & 1.27 (0.09 to 17.21$)$ & & 1.48 (0.09 to 24.47 ) & \\
\hline 2008 & 2.28 (0.19 to 27.47 ) & & 3.18 (0.22 to 46.49) & \\
\hline 2009 & $3.46(0.28$ to 42.10$)$ & & $4.61(0.31$ to 67.64$)$ & \\
\hline Male & 1.00 & \multirow{2}{*}{0.97} & 1.00 & \multirow{2}{*}{0.38} \\
\hline Female & 0.99 (0.70 to 1.42$)$ & & $1.13(0.86$ to 1.50$)$ & \\
\hline \multicolumn{5}{|l|}{ Age (years): } \\
\hline$<64$ & 1.00 & \multirow{4}{*}{$0.002^{\star}$} & 1.00 & \multirow{4}{*}{$0.30^{*}$} \\
\hline $65-74$ & 1.12 (0.70 to 1.78$)$ & & 1.17 (0.80 to 1.71$)$ & \\
\hline $75-84$ & 1.70 (1.05 to 2.77$)$ & & $1.23(0.84$ to 1.79$)$ & \\
\hline$\geq 85$ & $2.47(1.30$ to 4.71$)$ & & 1.25 (0.78 to 2.03$)$ & \\
\hline \multicolumn{5}{|l|}{ Ethnicity: } \\
\hline White & 1.00 & \multirow{3}{*}{0.01} & 1.00 & \multirow{3}{*}{0.19} \\
\hline Black & 1.90 (1.21 to 2.97$)$ & & $1.35(0.97$ to 1.87$)$ & \\
\hline Other & 1.27 (0.61 to 2.61$)$ & & 0.95 (0.52 to 1.72$)$ & \\
\hline \multicolumn{5}{|l|}{ Socioeconomic status: } \\
\hline Non-manual & 1.00 & \multirow{3}{*}{0.29} & 1.00 & \multirow{3}{*}{0.56} \\
\hline Manual & $1.22(0.82$ to 1.81$)$ & & 1.09 (0.79 to 1.49$)$ & \\
\hline Economically inactive & 0.85 (0.51 to 1.42$)$ & & 0.88 (0.57 to 1.35$)$ & \\
\hline \multicolumn{5}{|l|}{ Living conditions before stroke: } \\
\hline Alone in private accommodation & 1.00 & \multirow{3}{*}{0.70} & 1.00 & \multirow{3}{*}{0.75} \\
\hline With others in private accommodation & $1.16(0.81$ to 1.67$)$ & & 1.10 (0.82 to 1.48$)$ & \\
\hline Nursing home or other & $1.16(0.61$ to 2.21$)$ & & $1.16(0.71$ to 1.92$)$ & \\
\hline \multicolumn{5}{|l|}{ Stroke subtype: } \\
\hline Infarct & 1.00 & \multirow{2}{*}{0.05} & 1.00 & \multirow{2}{*}{$<0.001$} \\
\hline Haemorrhage & 0.61 (0.37 to 0.99$)$ & & $0.44(0.28$ to 0.70$)$ & \\
\hline \multicolumn{5}{|l|}{ Glasgow coma scale score: } \\
\hline «13 (impaired consciousness) & 1.00 & \multirow{2}{*}{$<0.001$} & 1.00 & \multirow{2}{*}{0.004} \\
\hline$\geq 13$ & $3.30(2.02$ to 5.42$)$ & & 1.86 (1.22 to 2.85$)$ & \\
\hline \multicolumn{5}{|l|}{ Incontinence: } \\
\hline No & 1.00 & & 1.00 & \\
\hline Yes & 1.61 (1.01 to 2.56$)$ & 0.04 & $2.23(1.58$ to 3.16$)$ & 8.001 \\
\hline Motor deficit: & & & & \\
\hline No & 1.00 & & 1.00 & \\
\hline Yes & 1.49 (0.94 to 2.37$)$ & 0.17 & $1.07(0.73$ to 1.57$)$ & 0.69 \\
\hline Swallow deficit: & & & & \\
\hline No & 1.00 & & 1.00 & \\
\hline Yes & 0.94 (0.58 to 1.53$)$ & 0.18 & 3.36 (2.26 to 4.99$)$ & 0.001 \\
\hline
\end{tabular}

All analyses are adjusted for age, sex, ethnicity, socioeconomic status, stroke subtype, level of consciousness, incontinence, motor deficit, dysphagia, and year of stroke. Analysis limited to patients admitted to hospital between 2005 and 2009.

*P trend.

study $(97 \%)$ were admitted to stroke units. Two of the three patients not admitted to a stroke unit after thrombolysis were admitted to the intensive care unit and one died before they could be admitted. A significant increase in the rate of thrombolysis was observed between 2005 and 2009 in our study, with the rate increasing to $20 \%$ among eligible patients in 2008 . This is higher than the thrombolysis rate of $10 \%$ reported in 2008 by the National Sentinel Stroke Audit. ${ }^{25}$ High rates of thrombolysis have, however, been reported when organised prehospital and emergency department acute stroke care have been implemented successfully. ${ }^{3738}$ In an Australian trial, interventions involving organised prehospital and emergency department acute stroke care increased the proportion of patients receiving thrombolysis from $4.7 \%$ to $21.4 \% .{ }^{37}$ Implementation of guidelines through the education of paramedic health professionals and communities promoted the safe administering of thrombolysis in community hospitals, with 
rates increasing in four of the six hospitals in the study ${ }^{38}$ Data from the national audit suggest that about $15 \%$ of unselected admissions are likely to be appropriate for thrombolysis if practitioners adhere to licensed indications, and up to $25 \%$ if the restriction on over 80 s is taken out. ${ }^{39}$ Evidence suggests that a relatively small number of centres in the United Kingdom successfully implement thrombolytic treatment, with significant inequity of access across the entire country. ${ }^{40}$ The National Sentinel Stroke Audit reported a significantly increased rate of thrombolysis in hospitals with larger numbers of eligible patients. ${ }^{25}$ The high rates of thrombolysis in this study could possibly reflect successful implementation of organised acute stroke care by hospitals in the study area and suggests the possibility that rates of thrombolysis can generally be improved when acute stroke care is effectively organised.

\section{Inequalities in access to acute stroke care}

Significant variations in investigation and management after an acute stroke have been reported among some sociodemographically defined groups. ${ }^{341}$ Inequalities were found in increased access to stroke units in the black population and lower odds for brain imaging in older patients and those of lower socioeconomic status. Possible explanations for the inequalities in access to stroke unit care include the impression that such care is only appropriate for certain subgroups of patients despite the evidence suggesting its beneficial effects on all patients with stroke. This study found that black patients and those with motor or swallowing deficits are more likely to be admitted to a stroke unit, yet the justification for the decision making is not evidence based. The higher odds of admission to a stroke unit and being in receipt of physiotherapy or occupational therapy in black people remained significant even after controlling for differences in age, stroke subtype, and severity. The observation that patients from ethnic minority groups receive effective interventions is rare in the literature, with many studies in cardiovascular disease showing lower uptakes in these groups. ${ }^{42-44} \mathrm{In}$ a nationally representative sample of Medicare patients in the United States, elderly black patients were found to have similar patterns of use of inpatient occupational and physiotherapy as white patients, after adjustment for the presence of a stroke related motor deficit and for other factors that are associated with the use of stroke rehabilitation services. ${ }^{45}$ This suggests that other factors apart from ethnicity explain observed ethnic patterns in the use of inpatient rehabilitation services for stroke. ${ }^{45}$ Black patients in south London were more likely to receive physiotherapy or occupational therapy after adjustment for the presence of motor deficits and other potentially confounding variables. It is possible that these findings are the result of other confounding factors not adjusted for in the models, such as cognitive impairment. Understanding the reasons behind this observed advantage in the black patients in this study may importantly inform practice for other interventions with lower uptake among minority populations.

As in previously reported studies, older patients in this study were less likely to undergo brain imaging. ${ }^{341}$ This association is partly explained by older patients being more likely to die before a scan could be done. It is, however, important to ensure that elderly patients are not excluded deliberately, as lower rates of brain imaging have implications in delivering effective acute treatment as well as the initiation of secondary prevention measures that could possibly result in poorer outcomes.

Previous studies have shown lower socioeconomic status to be associated with reduced access to care for a variety of medical services, even in countries with universal access to health. ${ }^{4647}$ A significant inverse association between socioeconomic status and receipt of brain imaging that was not explained by differences in ethnicity or case mix was observed in this study. It is not known whether the association was a result of patient factors, attitudes of health professionals, or the structure of the health systems. It is, however, possible that patients of lower socioeconomic status sought hospital care less often and less promptly and also had less information on the procedures and so had lower acceptance rates.

We did not find any significant association between sex and the receipt of interventions in our study, contrary to findings of other studies. ${ }^{4849}$

\section{Strengths and limitations of the study}

This study has strengths and limitations. Firstly, the regular adaptation of data collection forms to reflect changes in evidence has meant that some variables were missing at certain time points and some analyses had to be restricted to specific periods. Data were missing for some variables, which could potentially bias the results. However, the rate of missing data was generally low, with the highest rate recorded for speech deficits being $12 \%$. Furthermore, those with missing data on the process variables (admission to a stroke unit, brain imaging, swallow test, physiotherapy or occupational therapy, and speech and language therapy) as well as the receipt of aspirin within 48 hours did not differ by age, sex, ethnicity, or level of consciousness compared with those with no missing data. Despite these limitations, data for this study were derived from a well established, unique multiethnic population based stroke register, with the advantage to study trends in the process of stroke care over a 15 year period and ethnic differences in these processes. Arguably, no dataset globally would be representative to allow such analyses and trends over time. Data have been collected by applying a standardised protocol using multiple notification sources to ensure a near complete case ascertainment. Data from this study are locally representative, with formal capture-recapture estimates of $80 \%$ completeness. ${ }^{21}$ The findings from such a population based study provide representative evidence of stroke care in similar populations with similar provisions of healthcare. 


\section{WHAT IS ALREADY KNOWN ON THIS TOPIC}

Variations in processes of stroke care have been reported in observational studies and trials of acute stroke care

Audits from a selected sample of patients admitted to hospital suggest an improvement in the quality of stroke care in the United Kingdom over time, but information on the trends and associated factors of care from population based studies is limited

\section{WHAT THIS STUDY ADDS}

The proportion of patients receiving effective interventions for acute stroke care increased substantially in a multiethnic population during 1995 to 2009, yet with remaining inequalities of access to interventions that improve outcomes

Stroke unit care increased to $79 \%$, with inequalities in access by different ethnic groups

Strategies to minimise these inequalities will increase the chances that all patients receive optimal care with improved outcomes

\section{Conclusions and policy implications}

In conclusion, this study has shown significant, although not optimal, improvement over time in the receipt of acute interventions after a stroke in line with recommendations of current guidelines and identified factors associated with receipt of these interventions. The findings of this study suggest a disproportionate access to interventions in this population despite a government goal of universal access to healthcare. The study provides an important evaluation of evidence based practices to acute stroke care in a community in south London and provides the platform upon which to review the strengths, weaknesses, and opportunities for optimising access and delivery of acute stoke care in the United Kingdom and throughout the world.

We thank the patients, their families, and the healthcare professionals; the fieldworkers; and the team who have collected data for the South London Stroke Register since 1995.

Contributors: JA analysed and interpreted the data and wrote the paper. $A B, S C, A G R$, and CMCK participated in the refining of the study methods, analysis and interpretation of the data, and revised the article critically for important intellectual content. CDAW conceived and designed the study and revised the paper critically for important intellectual content, and is the guarantor. All authors gave final approval of the version to be submitted.

Funding: The study was funded by Guy's and St Thomas' Hospital Charity, The Stroke Association, Department of Health HQIP grants, UK, National Institute for Health Research programme grant (RP-PG-0407-10184).

The authors (CW) acknowledge financial support from the Department of Health through the National Institute for Health Research (NIHR) Biomedical Research Centre award to Guy's and St Thomas' NHS Foundation Trust in partnership with King's College London and the NIHR research for patient benefit programme award (PB-PG-0407-13228). CDAW is a senior investigator for the NIHR. AR is funded by the Guy's and St Thomas' NHS Trust AHSC PA Scheme.

Competing interests: All authors have completed the Unified Competing Interest form at www.icmje.org/coi_disclosure.pdf (available on request from the corresponding author) and declare: all authors had financial support from Department of Health through the National Institute for Health Research Biomedical Research Centre award to Guy's and St Thomas' NHS Foundation Trust in partnership with King's College London for the submitted work; no financial relationships with any organisations that might have an interest in the submitted work in the previous 3 years; no other relationships or activities that could appear to have influenced the submitted work.

Ethical approval: The study was approved by the ethics committees of Guy's and St Thomas' Hospital Trust, King's College Hospital, Queen's Square, and Westminster Hospital (London).

Data sharing: No additional data available.
1 Govan L, Weir C, Langhorne P for the Stroke Unit Trialists Collaboration. Organised inpatient (stroke unit) care for stroke. Cochrane Database Syst Rev 2007;4:CD000197.

2 Beech R, Ratcliffe M, Tilling K, Wolfe C. Hospital services for stroke care. A European perspective. European Study of Stroke Care. Stroke 1996;27:1958-64.

3 Bhalla A, Grieve R, Tilling K, Rudd AG, Wolfe CD: BIOMED II European Study of Stroke Care. Older stroke patients in Europe: stroke care and determinants of outcome. Age Ageing 2004;33:618-24.

4 Weir NU, Sandercock PA, Lewis SC, Signorini DF, Warlow CP. Variations between countries in outcome after stroke in the International Stroke Trial (IST). Stroke 2001;32:1370-7.

5 Grieve R, Hutton J, Bhalla A, Rastenyte D, Ryglewicz D, Sarti C, et al. A comparison of the costs and survival of hospital-admitted stroke patients across Europe. Stroke 2001;32:1684-91.

6 Wolfe C, Rudd A, Dennis M, Warlow C, Langhorne P. Taking acute stroke care seriously. In the absence of evidence we should manage acute stroke as a medical emergency. BMJ 2001;323:5-6.

7 Bhalla A, Tilling K, Kolominsky-Rabas P, Heuschmann P, Megherbi SE, Czlonkowska A, et al. Variation in the management of acute physiological parameters after ischaemic stroke: a European perspective. Eur J Neurol 2003;10:25-33.

8 McKevitt C, Coshall C, Tilling K, Wolfe C. Are there inequalities in the provision of stroke care? Analysis of an inner-city stroke register. Stroke 2005;36:315-20.

9 Bhalla A, Smeeton N, Rudd AG, Heuschmann P, Wolfe CD. A comparison of characteristics and resource use between in-hospital and admitted patients with stroke. I Stroke Cerebrovasc Dis 2010;19:357-63.

10 Adams HP Jr, del Zoppo G, Alberts MJ, Bhatt DL, Brass L, Furlan A et al. Guidelines for the early management of adults with ischemic stroke: a guideline from the American Heart Association/American Stroke Association Stroke Council, Clinical Cardiology Council, Cardiovascular Radiology and Intervention Council, and the Atherosclerotic Peripheral Vascular Disease and Quality of Care Outcomes in Research Interdisciplinary Working Groups: the American Academy of Neurology affirms the value of this guideline as an educational tool for neurologists. Stroke 2007;38:1655-711.

11 European Stroke Organisation Executive Committee. Guidelines for management of ischaemic stroke and transient ischaemic attack 2008. Cerebrovasc Dis 2008;25:457-507.

12 Royal College of Physicians Intercollegiate Stroke Working Party. National clinical guidelines for stroke.3rd ed. RCGP, 2008.

13 Kjellstrom T, Norving B, Shatchkute A. Helsingborg Declaration 2006 on European stroke strategies. Cerebrovasc Dis 2007;23:231-41.

14 National Stroke Foundation. Clinical guidelines for acute stroke management 2007.2nd ed. Australian Government, National Health and Medical Research Council, 2007.

15 Department of Health. National stroke strategy. 2007. www.dh.gov. uk/en/Publicationsandstatistics/Publications/ PublicationsPolicyAndGuidance/DH_081062.

16 National Audit Office. Reducing brain damage: faster access to better stroke care. NAO, 2005.

17 Department of Health. The national service framework for older people. $\mathrm{DH}, 2001$.

18 Irwin P, Hoffman A, Lowe D, Pearson M, Rudd AG. Improving clinical practice in stroke through audit: results of three rounds of National Stroke Audit. J Eval Clin Pract 2005;11:306-14.

19 Stewart JA, Dundas R, Howard RS, Rudd AG, Wolfe CD. Ethnic differences in incidence of stroke: prospective study with stroke register. BMJ 1999;318:967-71.

20 Tilling K, Sterne JA, Wolfe CD. Estimation of the incidence of stroke using a capture-recapture model including covariates. Int J Epidemiol 2001;30:1351-9.

21 Heuschmann PU, Grieve AP, Toschke AM, Rudd AG, Wolfe CD. Ethnic group disparities in 10-year trends in stroke incidence and vascular risk factors: the South London Stroke Register (SLSR). Stroke 2008;39:2204-10.

22 Teasdale G, Jennett B. Assessment of coma and impaired consciousness. A practical scale Lancet 1974:2:81-4.

23 Grimshaw JM, Russell IT. Effect of clinical guidelines on medical practice: a systematic review of rigorous evaluations. Lancet 1993:342:1317-22.

24 Rudd AG, Hoffman A, Irwin P, Lowe D, Pearson MG. Stroke unit care and outcome: results from the 2001 National Sentinel Audit of Stroke (England, Wales, and Northern Ireland). Stroke 2005;36:103-6.

25 Clinical effectiveness and evaluation unit: Royal College of Physicians. National sentinel stroke audit phase II (clinical audit). 2008. www.rcplondon.ac.uk/clinical-standards/ceeu/Current-work/ stroke/Documents/stroke-audit-report-2008.pdf.

26 Rothwell PM, Coull AJ, Giles MF, Howard SC, Silver LE, Bull LM, et al. Change in stroke incidence, mortality, case-fatality, severity, and risk factors in Oxfordshire, UK from 1981 to 2004 (Oxford Vascular Study). Lancet 2004;363:1925-33. 
27 Syme PD, Byrne AW, Chen R, Devenny R, Forbes JF. Community-based stroke incidence in a Scottish population: the Scottish Borders Stroke Study. Stroke 2005;36:1837-43.

28 Carter KN, Anderson CS, Hackett ML, Barber PA, Bonita R. Improved survival after stroke: is admission to hospital the major explanation? Trend analyses of the Auckland Regional Community Stroke Studies. Cerebrovasc Dis 2007;23:162-8.

29 Farooq MU, Reeves MJ, Gargano J, Wehner S, Hickenbottom S, Majid A: Paul Coverdell National Acute Stroke Registry Michigan Prototype Investigators. In-hospital stroke in a statewide stroke registry. Cerebrovasc Dis 2008;25:12-20.

30 Aly N, McDonald K, Leathley M, Sharma A, Watkins C. Retrospective case note review of acute and inpatient stroke outcomes. BMJ 2000;320:1511-2.

31 Bhalla A, Dundas R, Rudd AG, Wolfe CD. Does admission to hospital improve the outcome for stroke patients? Age Ageing 2001;30:197-203.

32 Meretoja A, Roine RO, Kaste M, Linna M, Roine S, Juntunen M, et al. Effectiveness of primary and comprehensive stroke centers: PERFECT stroke: a nationwide observational study from Finland. Stroke 2010;41:1102-7.

33 Saposnik G, Black SE, Hakim A, Fang J, Tu JV, Kapral MK, et al. Age disparities in stroke quality of care and delivery of health services. Stroke 2009; 40:3328-35.

34 Eriksson M, Glader EL, Norrving B, Terent A, Stegmayr B. Sex differences in stroke care and outcome in the Swedish national quality register for stroke care. Stroke 2009;40:909-14.

35 Reeves MJ, Arora S, Broderick JP, Frankel M, Heinrich JP, Hickenbottom S, et al. Acute stroke care in the US: results from 4 pilot prototypes of the Paul Coverdell National Acute Stroke Registry. Stroke 2005;36:1232-40.

36 Bray JE, Coughlan K, Bladin C. Thrombolytic therapy for acute ischaemic stroke: successful implementation in an Australian tertiary hospital. Intern Med J 2006;36:483-8.

37 Quain DA, Parsons MW, Loudfoot AR, Spratt NJ, Evans MK, Russell ML, et al. Improving access to acute stroke therapies: a controlled trial of organised pre-hospital and emergency care. Med ) Aust 2008;189:429-33.

38 Wojner-Alexandrov AW, Alexandrov AV, Rodriguez D, Persse D, Grotta JC. Houston paramedic and emergency stroke treatment and outcomes study (HoPSTO). Stroke 2005;36:1512-8.
39 Rudd AG, Hoffman A, Grant R, Campbell JT, Lowe D, on behalf of the Intercollegiate Working Party for Stroke. Stroke thrombolysis in England, Wales and Northern Ireland: how much do we do and how much do we need? J Neurol Neurosurg Psychiatry 2011;82:14-9.

40 Lees KR, Ford GA, Muir KW, Ahmed N, Dyker AG, Atula S, et al. Thrombolytic therapy for acute stroke in the United Kingdom: experience from the safe implementation of thrombolysis in stroke (SITS) register. QJM 2008;101:863-9.

41 Heidrich J, Heuschmann PU, Kolominsky-Rabas P, Rudd AG, Wolfe CD: European Biomed II Study of Stroke Care Group. Variations in the use of diagnostic procedures after acute stroke in Europe: results from the BIOMED II study of stroke care. Eur / Neurol 2007;14:255-61.

42 Johnston SC, Fung LH, Gillum LA, Smith WS, Brass LM, Lichtman JH, et al. Utilization of intravenous tissue-type plasminogen activator fo ischemic stroke at academic medical centers: the influence of ethnicity. Stroke 2001;32:1061-8.

43 Schwamm LH, Reeves MJ, Pan W, Smith EE, Frankel MR, Olson D, et al. Race/ethnicity, quality of care, and outcomes in ischemic stroke. Circulation 2010;121:1492-501.

44 Stansbury JP, Jia H, Williams LS, Vogel WB, Duncan PW. Ethnic disparities in stroke: epidemiology, acute care, and postacute outcomes. Stroke 2005;36:374-86.

45 Horner RD, Hoenig H, Sloane R, Rubenstein LV, Kahn KL. Racial differences in the utilization of inpatient rehabilitation services among elderly stroke patients. Stroke 1997;28:19-25.

46 Kapral MK, Wang H, Mamdani M, Tu JV. Effect of socioeconomic status on treatment and mortality after stroke. Stroke 2002;33:268-73.

47 Alter DA, Naylor CD, Austin PC, Chan BT, Tu JV. Geography and service supply do not explain socioeconomic gradients in angiography use after acute myocardial infarction. CMA/ 2003;168:261-4.

48 Di Carlo A, Lamassa M, Baldereschi M, Pracucci G, Basile AM, Wolfe $C D$, et al. Sex differences in the clinical presentation, resource use, and 3-month outcome of acute stroke in Europe: data from a multicenter multinational hospital-based registry. Stroke 2003;34:1114-9.

49 Glader EL, Stegmayr B, Norrving B, Terent A, Hulter-Asberg K, Wester PO, et al. Sex differences in management and outcome afte stroke: a Swedish national perspective. Stroke 2003;34:1970-5.

Accepted: 9 December 2010 